\title{
Effectiveness of Biosynthesized Trimetallic Au/Pt/Ag Nanoparticles on Planktonic and Biofilm Enterococcus faecalis and Enterococcus faecium Forms
}

\author{
Jolanta Dlugaszewska ${ }^{1}$ (D) Renata Dobrucka ${ }^{2}$
}

Received: 4 February 2019/Published online: 3 May 2019

(c) The Author(s) 2019

\begin{abstract}
A simple, effective and environmentally friendly green synthesis was demonstrated to obtain trimetallic Au/Pt/Ag nanoparticles using Lamii albi flos extract. The formed nanoparticles (NPs) were characterized by Ultraviolet-Visible, Fourier-Transform Infrared, Scanning Electron Microscopy, Transmission Electron Microscopy, and Atomic Force Microscopy measurements. The applied physicochemical methods indicated that the size of synthesized Au/Pt/Ag NPs was in the range of 35-40 nm. The antimicrobial activity of the obtained nanoparticles was assessed using Gram-positive, Gram-negative bacteria and yeasts, including standard strains of Staphylococcus aureus NCTC 4163, Enterococcus faecalis ATCC 29212, Escherichia coli ATCC 25922 and Candida albicans ATCC 10231. Also, antibacterial and antibiofilm activities of novel nanoparticles were studied using clinical strains of Enterococcus spp. The obtained Au/Pt/Ag NPs revealed excellent antimicrobial effects against planktonic and sessile clinical strains of Enterococcus faecalis and Enterococcus faecium.
\end{abstract}

Keywords Nanoparticles $\cdot$ Biosynthesis $\cdot$ Antimicrobial activity $\cdot$ Biofilm $\cdot$ Enterococcus spp

\section{Introduction}

In many studies, various nanoparticles (NPs) have revealed high toxicity to several microbes. Therefore, they have been considered as potential antimicrobial agents for novel applications in the medical and pharmaceutical fields $[1,2]$. The use of nanoparticles in medicine as an alternative or supplement to antibiotics has been increasing due to the widespread resistance of bacteria to antibiotics and the lack of effective novel antibiotic treatments.

Jolanta Dlugaszewska

jdlugasz@ump.edu.pl

Renata Dobrucka

renata.dobrucka@ue.poznan.pl

1 Department of Genetics and Pharmaceutical Microbiology, Poznan University of Medical Sciences, Swiecickiego 4, 60-781 Poznan, Poland

2 Department of Industrial Products Quality and Ecology, Faculty of Commodity Science, Poznan University of Economics, al. Niepodległości 10, 61-875 Poznan, Poland
In recent years, researchers have presented many biological methods for the synthesis of nanoparticles that can be considered as an alternative to chemical or physical methods [3, 4]. Biological methods for the production of nanoparticles have been reckoned safe and environmentally friendly. Moreover, they have been cost-effective and led to complete elimination of toxic chemicals [5]. The biological method is widely used in order to obtain monometallic nanoparticles. However, multi-component metal nanoparticles have revealed enhanced and cumulative properties of individual components $[6,7]$.

Among the leading species of broad antibiotic resistance are enterococci-commensal microbes that have become one of the most common pathogens in human infections along with medical progress. In many countries, Enterococcus faecalis (E. faecalis) and Enterococcus faecium (E. faecium) constitute one of the leading pathogens causing catheter-associated urinary tract infections (CAUTI), central line-associated bloodstream infection (CLABSI), wound and endodontic infections $[8,9]$. These enterococcal infections are difficult to treat due to the intrinsic resistance of enterococci to a broad spectrum of 
antimicrobials, their remarkable ability to acquire resistance mechanisms to many antibiotics and capacity of biofilm formation [10-13]. Biofilm is a three-dimensional structured, specialized community of irreversibly attached to various biotic and abiotic surfaces microorganisms, which are surrounded by an extracellular polymeric substance (EPS). Biofilm has numerous exciting properties, which give sessile bacterial cells resistance to many antimicrobial agents [14, 15].

In the present study, Lamii albi flos extract was applied for the preparation of trimetallic $\mathrm{Au} / \mathrm{Pt} / \mathrm{Ag}$ nanoparticles. Novel nanoparticles were screened regarding their antimicrobial activity as well as characterized against both planktonic and biofilm mode of living of Enterococcus faecalis and Enterococcus faecium clinical isolates.

\section{Materials and Methods}

\section{Preparation of Prepared Trimetallic Au/Pt/Ag Nanoparticles}

Lamii albi flos was collected from Wielkopolska region (Poland). Powdered L. albi flos (1 g) and suspended in the distilled water $(250 \mathrm{~mL})$ was heated and stirred vigorously for $60 \mathrm{~min}$ at $75{ }^{\circ} \mathrm{C}$. The obtained water extract was filtrated through Whatman's No. 1 filter paper, and the filtrate was applied for the preparation of solutions: I $(5 \mathrm{mM}$ $\left.\mathrm{AgNO}_{3}\right)$, II (5 mM HAuCl 4$)$ and III (5 $\left.\mathrm{mM} \mathrm{K}_{2} \mathrm{PtCl}_{6}\right)$. All solutions were combined in the 1:1:1 ratio and subsequently stirred for $24 \mathrm{~h}$ at $70{ }^{\circ} \mathrm{C}$. The UV-absorption spectrum of the trimetallic $\mathrm{Au} / \mathrm{Pt} / \mathrm{Ag}$ nanoparticles was monitored after $12 \mathrm{~h}, 18 \mathrm{~h}$, and $24 \mathrm{~h}$.

\section{Characterization of Prepared Trimetallic Au/Pt/ Ag Nanoparticles}

The optical properties of trimetallic Au/Pt/Ag nanoparticles biosynthesized using Lamii albi flos were analyzed via ultraviolet and visible absorption spectroscopy (spectrophotometer Cary E 500) in the range $200-800 \mathrm{~nm}$. The physicochemical properties (a type of connections and morphology) of trimetallic $\mathrm{Au} / \mathrm{Pt} / \mathrm{Ag}$ nanoparticles were studied with Fourier-Transform Infrared spectroscopy (FTIR), high resolution scanning electron microscope (HRSEM) Helios NanoLab 660 (FEI), an Atomic Force Microscope (Agilent 5500). The shape and size of the synthesized $\mathrm{Au}-\mathrm{Pt}$ nanoparticles were also analyzed using a transmission electron microscope (TEM) JEOL JEM 1200 EXII operating at an accelerated voltage of $200 \mathrm{keV}$.

\section{Microbial Isolates}

Standard strains of Staphylococcus aureus NCTC 4163, Enterococcus faecalis ATCC 29212, Escherichia coli ATCC 25922, Candida albicans ATCC 10231 were used for antimicrobial activity screening. Eight clinical strains of E. faecalis and E. faecium isolated from blood and urine were used for antibacterial and antibiofilm activity assessment. Bacterial strains were cultured aerobically in Brain Heart Infusion broth (BHI; bioMerieux, France) and Candida albicans in Sabouraud Dextrose Broth (SDB; OXOID, UK) at $36^{\circ} \mathrm{C} \pm 1{ }^{\circ} \mathrm{C}$ for $18-20 \mathrm{~h}$.

\section{Determination of the Minimal Inhibitory Concentration (MIC) and Minimal Biocidal Concentration (MBC)}

The antimicrobial activity of NPs was studied by employing a broth microdilution method following EUCAST (European Committee on Antimicrobial Susceptibility Testing) guidelines with modifications. Bacterial and $C$. albicans cultures were diluted in suitable broth (bacteria in Mueller-Hinton broth; MHB Oxoid, UK; $C$. albicans in SDB) to obtain a final suspension containing about $10^{6} \mathrm{CFU} / \mathrm{mL}$.

Stock solutions of NPs were two-fold serially diluted in an MHB (bacteria) and SDB (fungus) to concentrations ranging from 80 to $0.1563 \%$. In the study, $100 \mu \mathrm{L}$ of each dilution of NPs and sterile nutrient broth (for growth control) was dispensed into wells of microtitre plates (96 wells). Each well and wells containing only nutrient broth (growth control) were inoculated with $100 \mu \mathrm{L}$ of a microbial inoculum. All microtitre plates were incubated at $34 \pm 1{ }^{\circ} \mathrm{C}$ for $18 \mathrm{~h}$. The wells were then examined for evidence of growth and MICs values were determined as the lowest concentration that inhibited visible growth of the test microorganisms.

After recording the MIC endpoint, minimum biocidal concentration (MBC) was determined. For this purpose, concentrations equal to and higher than MIC were subcultured onto Trypticase Soy Agar (TSA; BioMerieux)bacteria and Sabouraud Dextrose Agar (SDA; OXOID, UK) - fungus. The MBC was defined as the lowest concentration at which no growth was observed. All tests were performed in triplicate, and the antibacterial activity was expressed as mean values \pm standard deviation (SD). Simultaneously, a test was carried out determining the antibacterial activity of Lamii albi flos extracts that were used for the synthesis of NPs. 


\section{Determination of the Bactericidal Effect of NPs on Planktonic Cells}

The bacteria grown in BHI were harvested by centrifugation $(3000 \times \mathrm{g}$ for $15 \mathrm{~min}$.) and re-suspended in $10 \mathrm{mM}$ phosphate buffered saline (PBS, $\mathrm{pH}=7.0$, SigmaAldrich $^{\circledR}$, USA) to a final concentration of ca. $10^{7} \mathrm{CFU} /$ $\mathrm{mL}$. Aliquots $(150 \mu \mathrm{L})$ of a standardized microbial suspension were placed into wells of a microtitre plate, and an equal volume of a solution of NPs was added to give final concentrations equal to MBC value. Control wells containing the bacterial suspension and PBS were used. After determined time viable bacteria were monitored and their number was calculated by counting colony forming units (CFUs) after appropriate dilution and inoculation on TSA plates at $34{ }^{\circ} \mathrm{C} \pm 1{ }^{\circ} \mathrm{C}$ for $24 \mathrm{~h}$. The number of surviving organisms and $\log _{10}$ reduction in microbial cells for each sample were calculated.

\section{Crystal Violet Biofilm Assay}

Biofilm formation was evaluated by the crystal violet assay proposed by Stepanovic et al. [16]. Overnight cultures of bacteria were diluted in BHI to density equal to 0.5 McFarland standard. Aliquots $(200 \mu \mathrm{L})$ of microbial suspensions were inoculated into 96-well flat-bottom microtiter plates and incubated at $36 \pm 1{ }^{\circ} \mathrm{C}$ for $24 \mathrm{~h}$. Negative control wells were included. The culture medium was then discarded from the microtiter plate, and the biofilms formed on the plates were washed three times with PBS to remove the planktonic cells. For quantitation, the biofilms were fixed with methanol for $15 \mathrm{~min}$, stained with $0.1 \%$ crystal violet for $15 \mathrm{~min}$, washed with PBS, and air-dried. Crystal violet bound to the adherent cells was solubilized with $200 \mu \mathrm{L}$ of ethanol-acetone $(80: 20, \mathrm{vol} / \mathrm{vol})$ and the optical density (OD) of the solubilized dye was measured using an Infinite M200 (Tecan) plate reader at $590 \mathrm{~nm}$. Negative controls were used to set background optical density. Readings from triplicate wells were averaged.

The interpretation of biofilm formation was made according to the criteria of Stepanovic et al. [16] as follows: ODc $=$ mean OD of negative control $+3 \mathrm{SD}$; those with $\mathrm{OD} \leq \mathrm{ODc}$ were classified as biofilm negative; those with $\mathrm{ODc}<\mathrm{OD} \leq 2 \mathrm{x}$ ODc were classified as weak biofilm producers; $2 \mathrm{x}$ ODc $<$ OD $\leq 4 \mathrm{x}$ ODc-moderate biofilm producers; $4 \mathrm{x}$ ODc $<\mathrm{OD}$ - strong biofilm producers.

\section{Determination of Viable Cells in the Biofilm}

Overnight cultures of bacteria were diluted in BHI to density equal to 0.5 McFarland standard. Aliquots $(200 \mu \mathrm{L})$ of microbial suspensions were inoculated into 96-well flat-bottom microtiter plates and incubated at $36 \pm 1{ }^{\circ} \mathrm{C}$. At the determined times $(24 \mathrm{~h}, 48 \mathrm{~h}, 72 \mathrm{~h})$, the culture medium was discarded from the microtiter plate, and the biofilms formed on the plates were washed three times with PBS to remove the planktonic cells. The biofilms were scraped carefully and homogenized. Samples were diluted serially in PBS. The number of CFU in PBS was counted using the serial dilution-agar plate surface spread method. The total number of CFU was calculated. The result was given as the average of three outcomes.

\section{Antibiofilm Assay}

To quantify the efficiency of biofilm killing, biofilms were developed in a 96-well microtiter plate for $72 \mathrm{~h}$, as described above. The incubation medium was removed, and the wells were gently washed three times with PBS to remove non-adherent cells. Subsequently, $300 \mu \mathrm{L}$ aliquots of NPs solutions were added. After a determined time, NPs solutions were discarded, and the biofilms formed on the plates were washed three times with PBS. The biofilms were scraped carefully and homogenized. Samples were diluted serially in PBS, plated on the TSA and incubated $24 \mathrm{~h}$ at $36^{\circ} \mathrm{C} \pm 1{ }^{\circ} \mathrm{C}$. Simultaneously, an antibiofilm assay for Lamii albi flos extracts was carried. The number of CFU were counted, and the number of surviving organisms and the $\log _{10}$ reduction in microbial cells for each sample were calculated.

\section{Statistical Analysis}

For data analysis, the number of bacteria was expressed as $\log _{10} \mathrm{CFU} / \mathrm{mL}$ (Colony Forming Units). The data were presented as mean $\pm \mathrm{SD}$ of three independent experiments using the respective formulas in Microsoft Excel.

\section{Results and Discussion}

\section{Physicochemical Characterization}

\section{UV-Vis Analysis}

The optical properties of the trimetallic Au/Pt/Ag NPs were measured using the UV-Vis spectroscopy. Figure 1 presents the UV-visible spectra of the trimetallic $\mathrm{Au} / \mathrm{Pt} / \mathrm{Ag}$ NPs biosynthesized using $L$. albi flos. The absorbance was read $12 \mathrm{~h}, 18 \mathrm{~h}$, and $24 \mathrm{~h}$ after mixing the solutions at $70{ }^{\circ} \mathrm{C}$. After $24 \mathrm{~h}$, peaks related to nanoparticles in the region of $580 \mathrm{~nm}$ and $450 \mathrm{~nm}$ were observed, which confirmed the appearance of $\mathrm{Au}$ and $\mathrm{Ag}$ nano form in this solution. According to the literature, the wide peak in the area of $450 \mathrm{~nm}$ represents the formation of silver 
Fig. 1 UV-Visible spectra of the trimetallic $\mathrm{Au} / \mathrm{Pt} / \mathrm{Ag}$ nanoparticles biosynthesized using $L$. albi flos

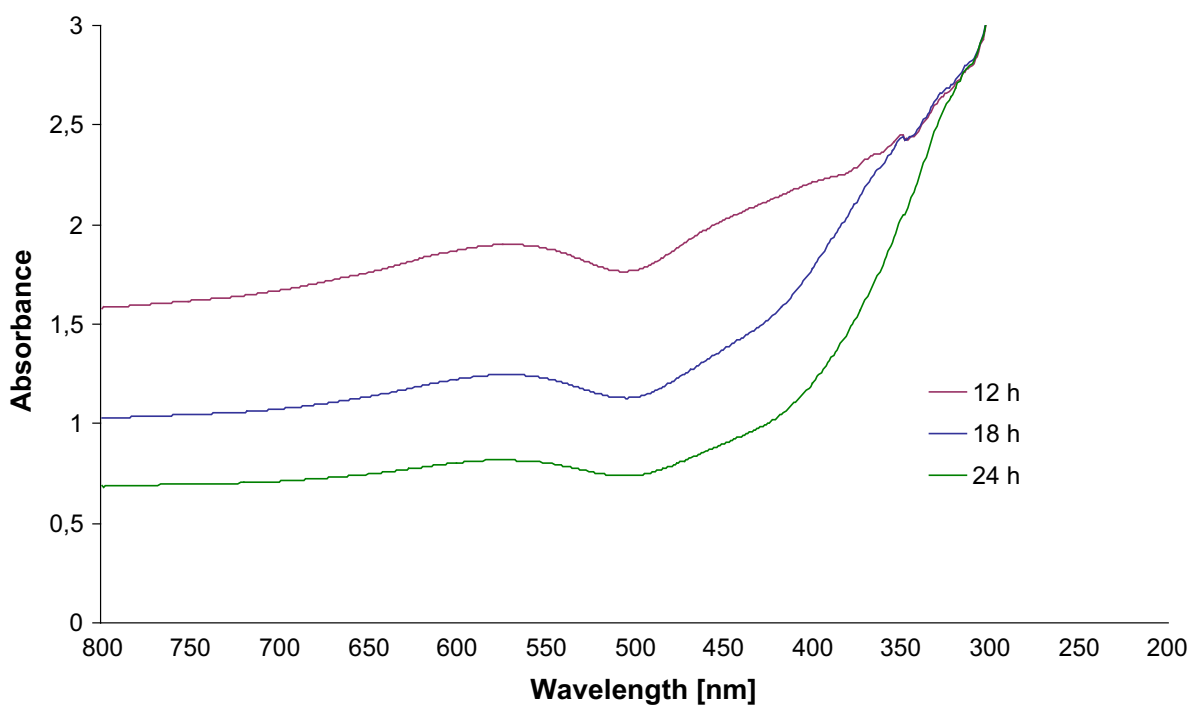

nanoparticles [17-19]. As regards nanoparticles, the studies carried out by López-Muñoz et al. [20] showed that the thermal diffusivity ratio changed inversely with the nanoparticle size. The effect was studied in a size range of $16-125 \mathrm{~nm}$ for gold nanofluids. The thermal diffusivity ratio has been found to increase with concentration.

After 12 and $18 \mathrm{~h}$, the peak was observed at $350 \mathrm{~nm}$. It suggested the presence of $\mathrm{Pt}$ ions in the studied mixture. However, after $24 \mathrm{~h}$ of reaction at $70^{\circ}$, the absorption peak at $350 \mathrm{~nm}$ disappeared, which was the evidence of the complete reduction of $\mathrm{Pt}^{4+}$. The similar results were obtained by Yadav et al. [21] for the trimetallic Au/Pt/Ag, where one single absorption peak centered around $527 \mathrm{~nm}$ was observed. Also, in the studies of Karthikeya et al. [22] the spectrum of dispersion of $\mathrm{Au} / \mathrm{Pt} / \mathrm{Ag}$ trimetallic nanocomposites has revealed an evident single absorbance at $528 \mathrm{~nm}$.

\section{FTIR Analysis}

Figure 2 presents the FTIR spectra of (A) Lamii albi flos extract and (B) trimetallic Au/Pt/Ag NPs. Figure 2a presents the intensive signals which were observed at $3323 \mathrm{~cm}^{-1}, \quad 2091 \mathrm{~cm}^{-1}, \quad 1635 \mathrm{~cm}^{-1}, \quad 419 \mathrm{~cm}^{-1}$ and $384 \mathrm{~cm}^{-1}$. In Fig. $2 \mathrm{~b}$ the strong peaks were observed at $3295 \mathrm{~cm}^{-1}, 2216 \mathrm{~cm}^{-1}, 1634 \mathrm{~cm}^{-1}, 391 \mathrm{~cm}^{-1}, 410 \mathrm{~cm}^{-1}$ and $422 \mathrm{~cm}^{-1}$. The strong peaks at $3323 \mathrm{~cm}^{-1}$ and $3295 \mathrm{~cm}^{-1}$ stretching in FTIR correspond to the $\mathrm{OH}$ groups. The intensive peaks at $2091 \mathrm{~cm}^{-1}$ and $2216 \mathrm{~cm}^{-1}$ indicated the presence of the alkyne group. The most intense bands at $1634 \mathrm{~cm}^{-1}$ and $1635 \mathrm{~cm}^{-1}$ correspond to amide bonds of proteins that may arise due to carboxyl stretching. The bands at $419 \mathrm{~cm}^{-1}$ and $384 \mathrm{~cm}^{-1}$ were attributed to the deformation vibration of $\mathrm{C}-\mathrm{C}$ in polymer chains. The absorption bands at $391 \mathrm{~cm}^{-1}, 410 \mathrm{~cm}^{-1}$ and
$422 \mathrm{~cm}^{-1}$ indicated the formation of metal-biomolecules present in the sample (Fig. 2b). The FTIR studies confirm the presence of active compounds in Lamii albi flos. According to the literature, Lamii albi flos contains phenolic acids, iridoids, essential oil, tannins, xanthophylls, saponins, mucilage, alkaloids, choline, flavonoids, lamalboside and tyramine [23]. Phenolic acids are known to have antioxidant properties. In numerous studies on the antioxidant properties of phenolic acids, the scientists have shown that those characteristics depend on the chemical structure, i.e. they are related to the number of hydroxyl groups in the particle and the degree of their esterification. In compounds that have one hydroxyl group, the antioxidant activity is additionally increased by the presence of one or two methoxy groups in the ring. The introduction of a group with electron donors, i.e. an alkyl group or a methoxy group, in the orto- position strengthens the stability of the antioxidant properties of phenolic acids [24]. Chlorogenic acid present in Lamii albi flos exhibits strong antioxidant activity. Lamii albi flos also contains cinnamic acid, which exhibits antioxidant effects as well. They stem from its ability to donate the proton and create a stable and not very reactive phenoxyl radical [25].

\section{SEM and TEM Analysis}

In Fig. 3, the SEM and TEM images of the trimetallic Au/ $\mathrm{Pt} / \mathrm{Ag}$ NPs biosynthesized using L.albi flos were presented. The morphology of the trimetallic Au/Pt/Ag NPs was studied using scanning electron microscopy (SEM). Figure 3a-d present the SEM images of the trimetallic Au/Pt/ $\mathrm{Ag}$ nanoparticles at different magnifications (respectively $500 \times, 1500 \times, 5000 \times$ and $10,000 \times)$. The mean diameter of the obtained trimetallic $\mathrm{Au} / \mathrm{Pt} / \mathrm{Ag}$ nanoparticles is ca. $40 \mathrm{~nm}$. In the Transmission Electron Microscopy (TEM) 


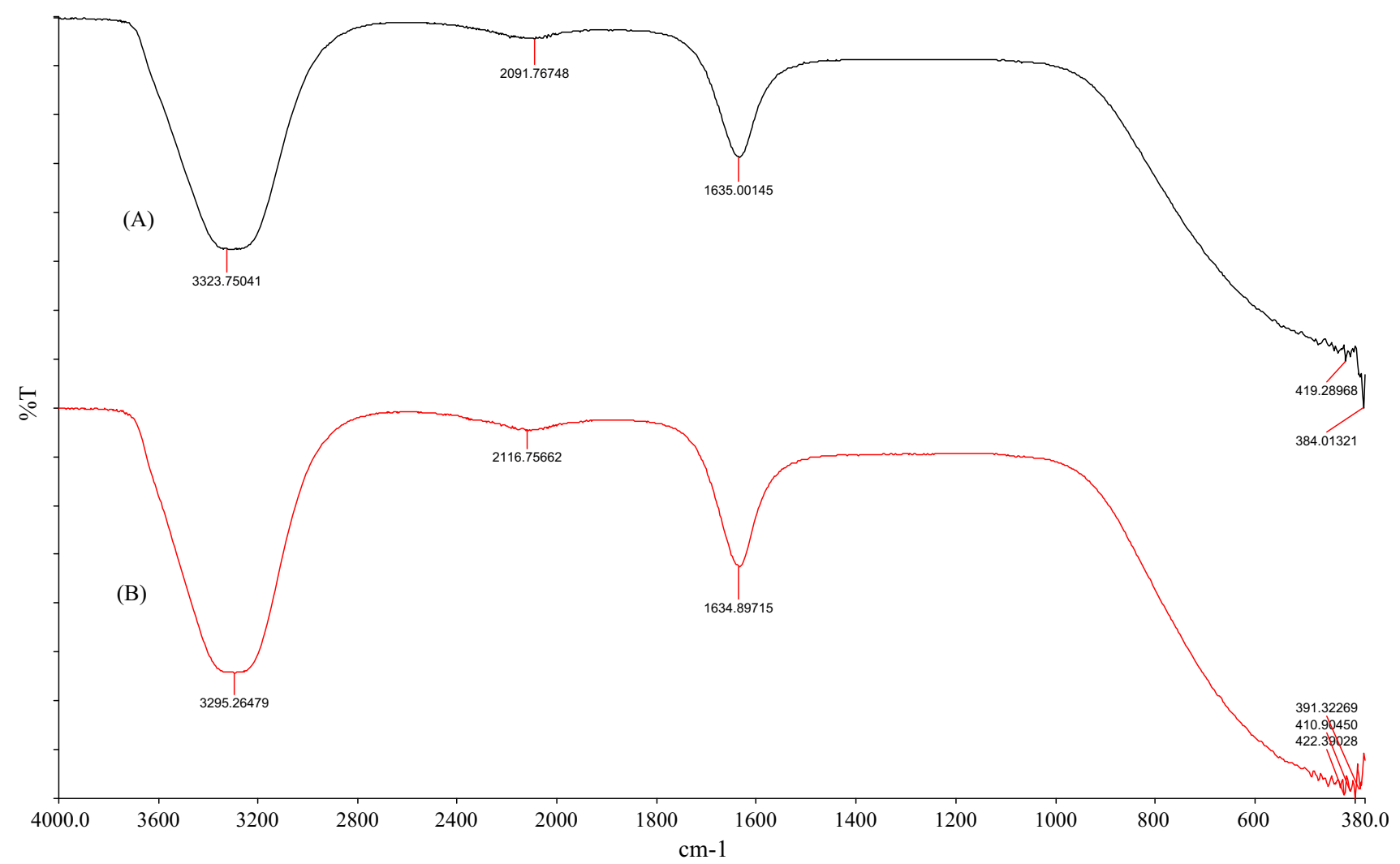

Fig. 2 FTIR spectra of the trimetallic Au/Pt/Ag nanoparticles biosynthesized using L.albi flos

images they present mainly spherical shape. The TEM images (Fig. 3e, f at the scale bar $100 \mathrm{~nm}$ ) confirmed that the size of the trimetallic $\mathrm{Au} / \mathrm{Pt} / \mathrm{Ag}$ nanoparticles was about $40 \mathrm{~nm}$.

\section{AFM Analysis}

The analysis of the trimetallic Au/Pt/Ag NPs biosynthesized using L. albi flos was enriched in the Atomic Force Microscopy (AFM). The size of the studied trimetallic Au/ Pt/Ag NPs was assessed to be about $35 \mathrm{~nm}$, thus confirming the previously obtained SEM and TEM data. In Fig. 4 the AFM image of trimetallic Au/Pt/Ag NPs biosynthesized using L.albi flos was presented where (a) the topography is $10 \mu \mathrm{m} \times 10 \mu \mathrm{m}$, (b) the topography is $3 \mu \mathrm{m} \times 3 \mu \mathrm{m}$, (c) the topography is $3 \mu \mathrm{m} \times 3 \mu \mathrm{m}$ with selected profile, (d) the selected profile of nanoparticles.

\section{Antimicrobial Activity Study}

Antimicrobial activity of trimetallic $\mathrm{Au} / \mathrm{Pt} / \mathrm{Ag} \mathrm{NPs}$, synthesized using Lamii albi flos, against planktonic cells of standard strains of bacteria and fungus was estimated by minimal inhibitory concentration (MIC) and minimal biocidal concentration (MBC) determination. Tested Au/Pt/Ag NPs showed reproducible excellent bacteriostatic and bactericidal activity against all used bacterial standard strains and good antifungal activity against Candida albicans ATCC 10231 (Table 1). To exclude the possibility of plant extracts influence on $\mathrm{Au} / \mathrm{Pt} / \mathrm{Ag}$ NPs antimicrobial activity, the Lamii albi flos extracts were also tested. The antimicrobial activity of the Lamii albi flos extracts was not found in the studies - the growth of bacteria was not inhibited at used concentrations. Thus it was confirmed that the observed wide-spectrum antimicrobial activity correlates with the presence of trimetallic $\mathrm{Au} / \mathrm{Pt} / \mathrm{Ag}$ NPs.

\section{The Impact of NPs on Planktonic Enterococcus spp.}

The effect of Au/Pt/Ag NPs toxicity on eight clinical $E$. faecalis and E. faecium isolates was evaluated by determining $\mathrm{MIC}, \mathrm{MBC}$ and the reduction in bacterial cell number (Table 2). After determination of MIC and MBC, the enterococcal strains were exposed to $\mathrm{Au} / \mathrm{Pt} / \mathrm{Ag} \mathrm{NPs}$ at concentration equal to $\mathrm{MBC}$ value. At the selected time ( $5 \mathrm{~min}$ ), $50 \mu \mathrm{L}$ of the solution was sampled, diluted and cultured on TSA plates and the number of CFU per mL was calculated.

The initial number of bacteria was also determined. The CFU data were converted to log CFU, and the logarithmic reduction factor was calculated. In our study, all used strains were inactivated with $\mathrm{Au} / \mathrm{Pt} / \mathrm{Ag} \mathrm{NPs}$ at tested 
Fig. 3 SEM images of the trimetallic $\mathrm{Au} / \mathrm{Pt} / \mathrm{Ag}$ nanoparticles biosynthesized using L.albi flos with magnification $\mathbf{a} \times 500$, b $\times 1500, \mathbf{c} \times 5000, \mathbf{d} \times 10,000$ and TEM images $\mathbf{e}$ and $\mathbf{f}$ where the scale bar is $100 \mathrm{~nm}$ (a)

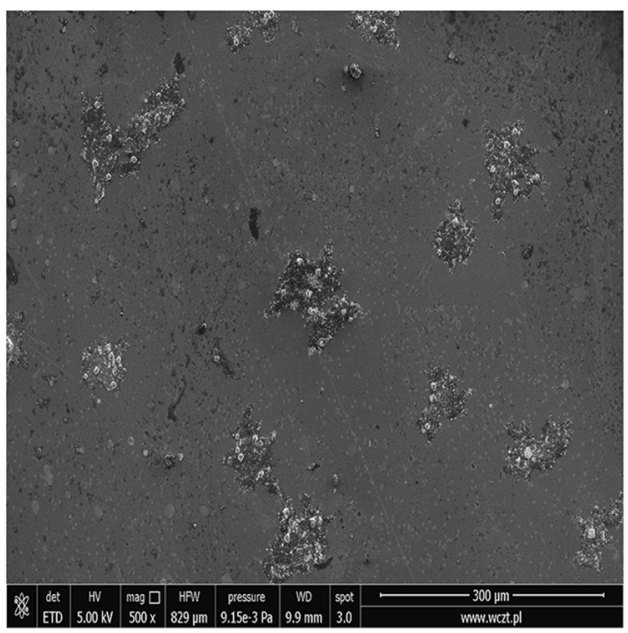

(c)

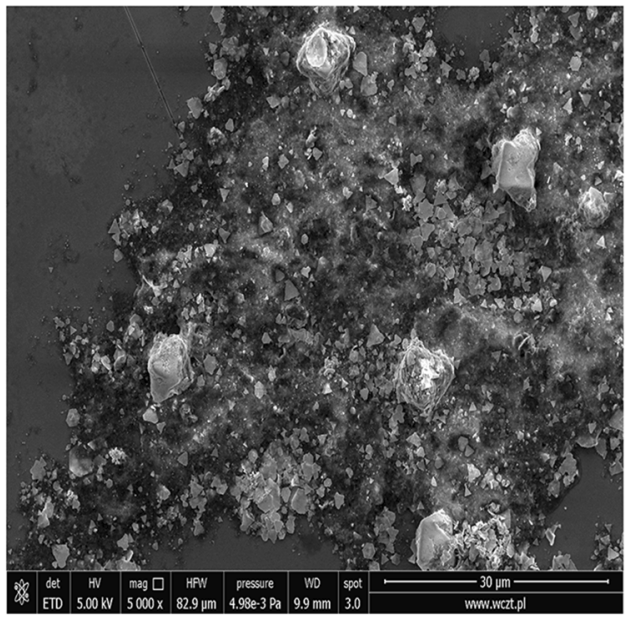

(e)

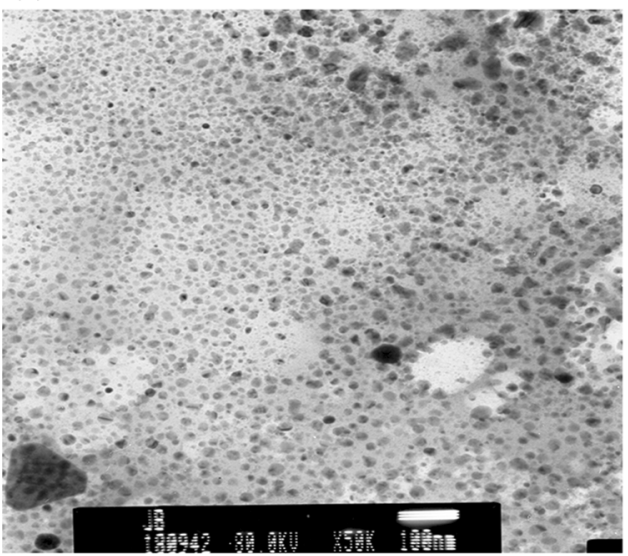

(b)

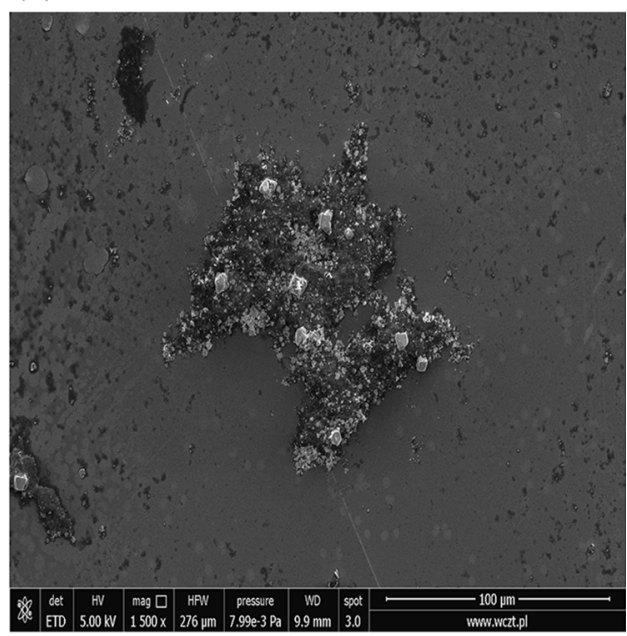

(d)

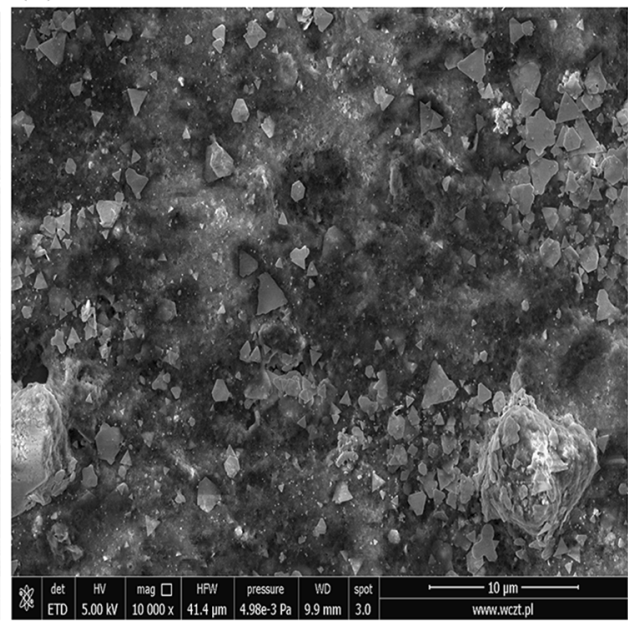

(f)

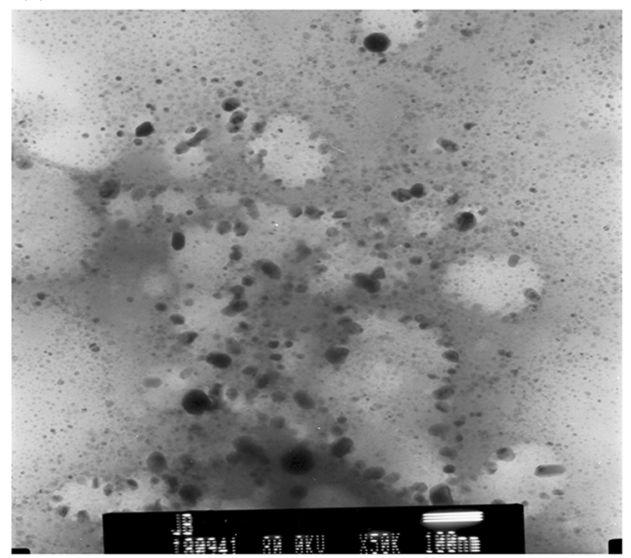

conditions. No bacteria were isolated after treatment with $\mathrm{Au} / \mathrm{Pt} / \mathrm{Ag} \mathrm{NPs}$, and the number of viable cells was reduced of more than 5 logs. The differences in the value of $\mathrm{R}$ factor results with differences in an initial number of tested strains cells. Neither bacterial species (E. faecalis, E. faecium) nor the strain source (blood, urine) was associated with the susceptibility to $\mathrm{Au} / \mathrm{Pt} / \mathrm{Ag}$ NPs.

Due to the tremendous toxicity against potential pathogens, a large number of nanoparticles have been studied in many antimicrobial applications, including the medical field [26-28]. Among the metallic nanomaterials, silver 
Fig. 4 AFM images of the trimetallic $\mathrm{Au} / \mathrm{Pt} / \mathrm{Ag}$ nanoparticles biosynthesized using L.albi flos where a the topography is $10 \mu \mathrm{m} \times 10 \mu \mathrm{m}$, b the topography is

$3 \mu \mathrm{m} \times 3 \mu \mathrm{m}, \mathbf{c}$ the topography is $3 \mu \mathrm{m} \times 3 \mu \mathrm{m}$ with selected profile, $\mathbf{d}$ the selected profile of nanoparticles
Table 1 The activity of $\mathrm{Au} / \mathrm{Pt} /$ Ag NPs against standard microbial strains (a)

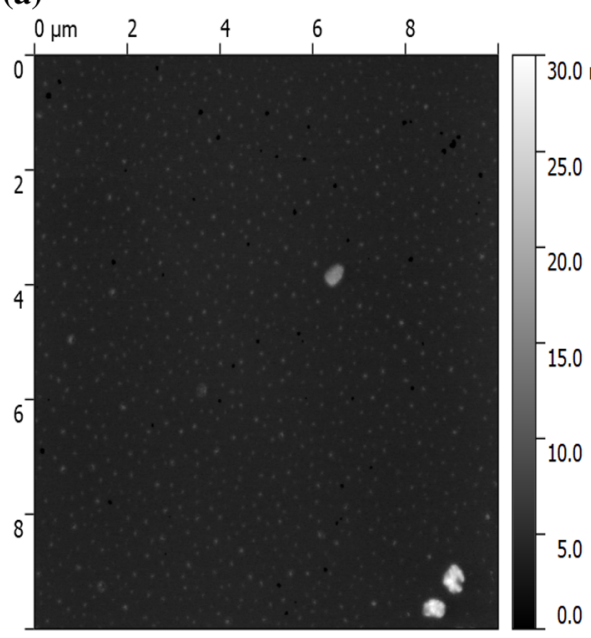

(b)

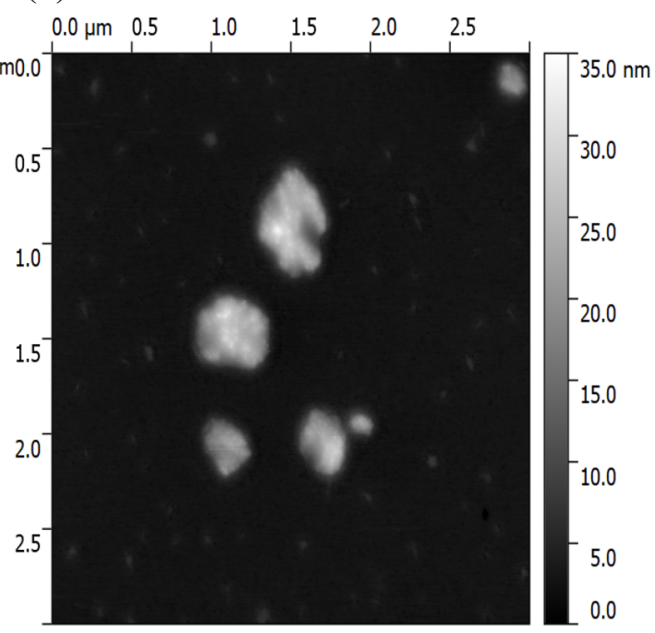

(c)

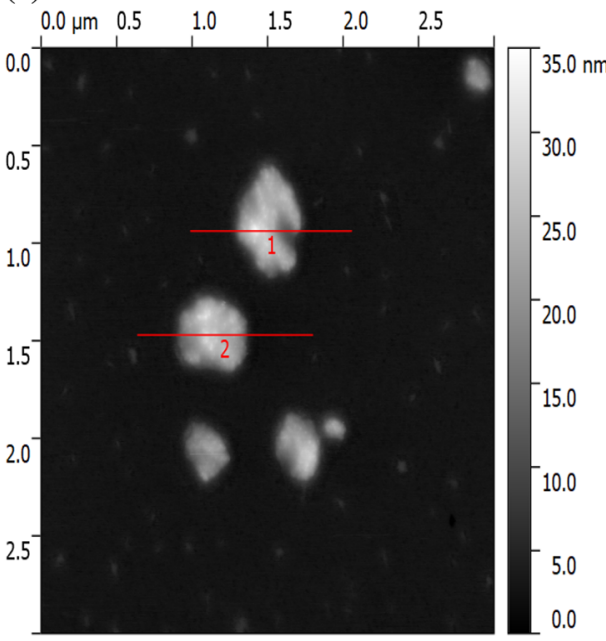

(d)

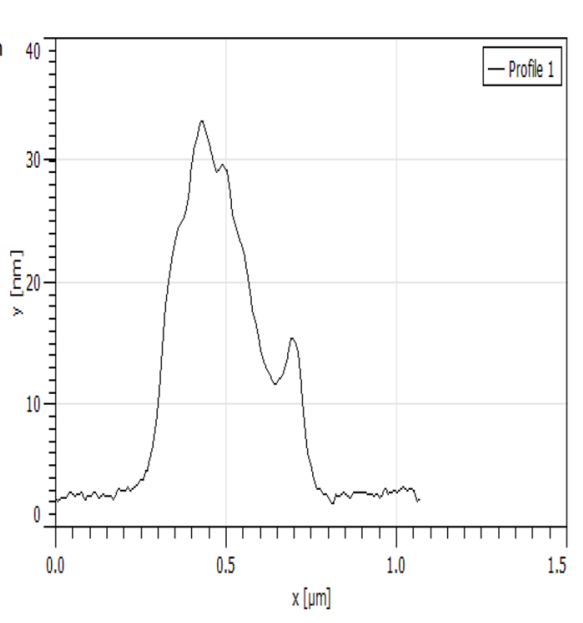

\begin{tabular}{|c|c|c|c|c|}
\hline \multirow[t]{2}{*}{ Microorganism } & \multicolumn{2}{|c|}{$\mathrm{Au} / \mathrm{Pt} / \mathrm{Ag} \mathrm{NPs}$} & \multicolumn{2}{|l|}{ Control } \\
\hline & $\begin{array}{l}\mathrm{MIC} \pm \mathrm{SD} \\
(\%)\end{array}$ & $\begin{array}{l}\mathrm{MBC} \pm \mathrm{SD} \\
(\%)\end{array}$ & $\begin{array}{l}\text { MIC } \\
(\%)\end{array}$ & $\begin{array}{l}\text { MBC } \\
(\%)\end{array}$ \\
\hline Staphylococcus aureus NCTC 4163 & $10.0 \pm 0.0$ & $20.0 \pm 0.0$ & $>40.0$ & $>40.0$ \\
\hline Enterococcus faecalis ATCC 29212 & $10.0 \pm 0.0$ & $20.0 \pm 0.0$ & $>40.0$ & $>40.0$ \\
\hline Escherichia coli ATCC 25922 & $10.0 \pm 0.0$ & $16.7 \pm 5.8$ & $>40.0$ & $>40.0$ \\
\hline Candida albicans ATCC 10231 & $20.0 \pm 0.0$ & $40.0 \pm 0.0$ & $>40.0$ & $>40.0$ \\
\hline
\end{tabular}

Control-Lamii albi flos extract

$M I C$ minimal inhibitory concentration, $M B C$ minimal biocidal concentration, $S D$ standard deviation nanoparticles are of the greatest interest due to their particular physical and chemical properties and biocidal activity against wide range of microorganisms [29-31]. Other noble metal nanoparticles including gold and platinum nanoparticles have proved some antimicrobial activity [32-36].
It has been suggested that the antimicrobial effect of metal nanoparticles comes from a combination of several effects, including their interaction with cell membranes causing structural changes in permeability and disruption, generation of free radicals, deactivation of vital enzymes by reaction between thiol groups and metal ions released from nanoparticles, destruction of microbial DNA and 
Table 2 Effect of $\mathrm{Au} / \mathrm{Pt} / \mathrm{Ag}$ NPs on planktonic enterococcal strains

\begin{tabular}{lllll}
\hline Tested strain [No.] & Source of isolation & $\begin{array}{l}\text { MIC } \pm \text { SD } \\
(\%)\end{array}$ & $\begin{array}{l}\text { MBC } \pm \text { SD } \\
(\%)\end{array}$ & R \pm SD \\
\hline Enterococcus faecalis [2008] & Blood & $10 \pm 0.0$ & $20 \pm 0.0$ & $>5.45^{1} \pm 0.08$ \\
Enterococcus faecium [3915] & Blood & $10 \pm 0.0$ & $20 \pm 0.0$ & $>5.37^{1} \pm 0.10$ \\
Enterococcus faecium [4150] & Urine & $10 \pm 0.0$ & $20 \pm 0.0$ & $>5.33^{1} \pm 0.13$ \\
Enterococcus faecium [4489] & Blood & $10 \pm 0.0$ & $20 \pm 0.0$ & $>5.50^{1} \pm 0.19$ \\
Enterococcus faecalis [4601] & Blood & $10 \pm 0.0$ & $20 \pm 0.0$ & $>5.39^{1} \pm 0.08$ \\
Enterococcus faecalis [4801] & Urine & $10 \pm 0.0$ & $20 \pm 0.0$ & $>5.25^{1} \pm 0.07$ \\
Enterococcus faecalis [4923] & Urine & $10 \pm 0.0$ & $20 \pm 0.0$ & $>5.47^{1} \pm 0.11$ \\
Enterococcus faecium [5256] & Blood & $10 \pm 0.0$ & $20 \pm 0.0$ & $>5.45^{1} \pm 0.03$ \\
Enterococcus faecalis ATCC 29212 & - & $10 \pm 0.0$ & $20 \pm 0.0$ & $>5.51^{1} \pm 0.16$ \\
\hline
\end{tabular}

$\log _{10}$ reduction was determined at concentration of Au/Pt/Ag NPs equal MBC (20.0\%)

$\log _{10}$ reduction $=\log _{10}(\mathrm{~A})-\log _{10}(\mathrm{~B}) ; \mathrm{A}$-number of viable bacteria before treatment with $\mathrm{Au} / \mathrm{Pt} / \mathrm{Ag}$ NPs; B-number of viable bacteria after treatment with Au/Pt/Ag NPs for 5 min

MIC - minimal inhibitory concentration; $\mathrm{MBC}-$ minimal biocidal concentration; $\mathrm{R}-\log _{10}$ reduction in viable count; SD—standard deviation

${ }^{1}$ No recovery
RNA, as well as lysis of microbial cells [37-39]. Recent studies have provided evidence that oxidation and ion release may play a preponderant role in the mode of action of Ag NPs. These NPs act mainly by the damage the cell membranes, binding to and inactivating proteins, inhibiting the replication of DNA [40-42].

The antimicrobial mechanisms of Au NPs include changing the membrane potential, inhibition of ATP synthase activities and a decrease in metabolism, and inhibition of the subunit of ribosome for tRNA binding and failure of biological processes. In contrast to AgNPs, $\mathrm{Au}$ NPs has not generated any free radicals [35, 43]. The effects of Pt NPs on microbial cells remain unclear. It is suggested that Pt NPs kill bacteria through disruption of the cell envelope, the production of reactive oxygen species and directly linkage of DNA molecules and damage to the DNA structure [44-46].

Although, there have been numerous publications on the biosilver nanoparticles antimicrobial activity and many studies have investigated antibacterial activity of AuNPs and PtNPs, very exiguous reports are available concerning biocidal properties of trimetallic $\mathrm{Au} / \mathrm{Pt} / \mathrm{Ag}$ nanoparticles [47, 48]. Yadav et al. [21] have observed the synergistic antimicrobial activity of trimetallic $\mathrm{Au} / \mathrm{Pt} / \mathrm{Ag}$ nanoparticlebased nanofluid and this combination exhibited better antibacterial properties than bimetallic and single metallic nanofluid. The $\mathrm{Au}, \mathrm{Au} / \mathrm{Pt}$ and $\mathrm{Au} / \mathrm{Pt} / \mathrm{Ag}$ nanofluids were prepared by microwave irradiation method. The synergistic effects of metals or their complexes have also been demonstrated $[49,50]$.

In this investigation trimetallic $\mathrm{Au} / \mathrm{Pt} / \mathrm{Ag}$ nanoparticles were synthesized using a biological method that is safe and eco-friendly. What is worth emphasizing, the use of a combination of $\mathrm{Ag}, \mathrm{Au}$, and $\mathrm{Pt}$ allows lowering the concentration of Ag, which is more toxic than Au and Pt. Also, gold and platinum have excellent antioxidant properties [51-53].

\section{The Effect of Trimetallic Au/Pt/Ag NPs on Mature Enterococcal Biofilms}

Biofilm has important implications for the pathogenesis, treatment, and prevention of infection [54-56]. The ability of pathogens to form biofilm is one of the major virulence factors.

Crystal Violet biofilm assay differentiated the studied enterococcal isolates into (1) non biofilm-producing (4 strains); (2) weak biofilm-producing (2 strains); and (3) moderate biofilm-producing (3 strains) (Fig. 5a). The number of microorganisms in the biofilm increased with prolonged incubation time, and after $72 \mathrm{~h}$ of incubation, the recovery of viable cells was the highest for all tested strains (Fig. 5b). For this reason, for the further study, we used $72 \mathrm{~h}$ biofilm.

One of the most critical features of bacteria living in biofilms is their decreased sensitivity to antimicrobial substances. Bacteria living in biofilm state can be about 1000-fold more resistant towards antimicrobials than their planktonic counterparts [57-59].

It may result from tolerance or resistance to biocidal substances, the presence of a polymer matrix, slowing down the growth of bacteria in the deeper layers, partial pressure of oxygen and carbon dioxide, the concentration of hydrogen ions and adoption of a distinct biofilm phenotype, which differs from that of their planktonic counterparts $[60,61]$. 
Fig. 5 Biofilm formation in the enterococcal isolates. a Crystal violet biofilm assay;

ODc $=$ mean OD of negative control $+3 \mathrm{SD} ; \mathbf{b}$ the viable cell counts recovered from Enterococcus spp. biofilms
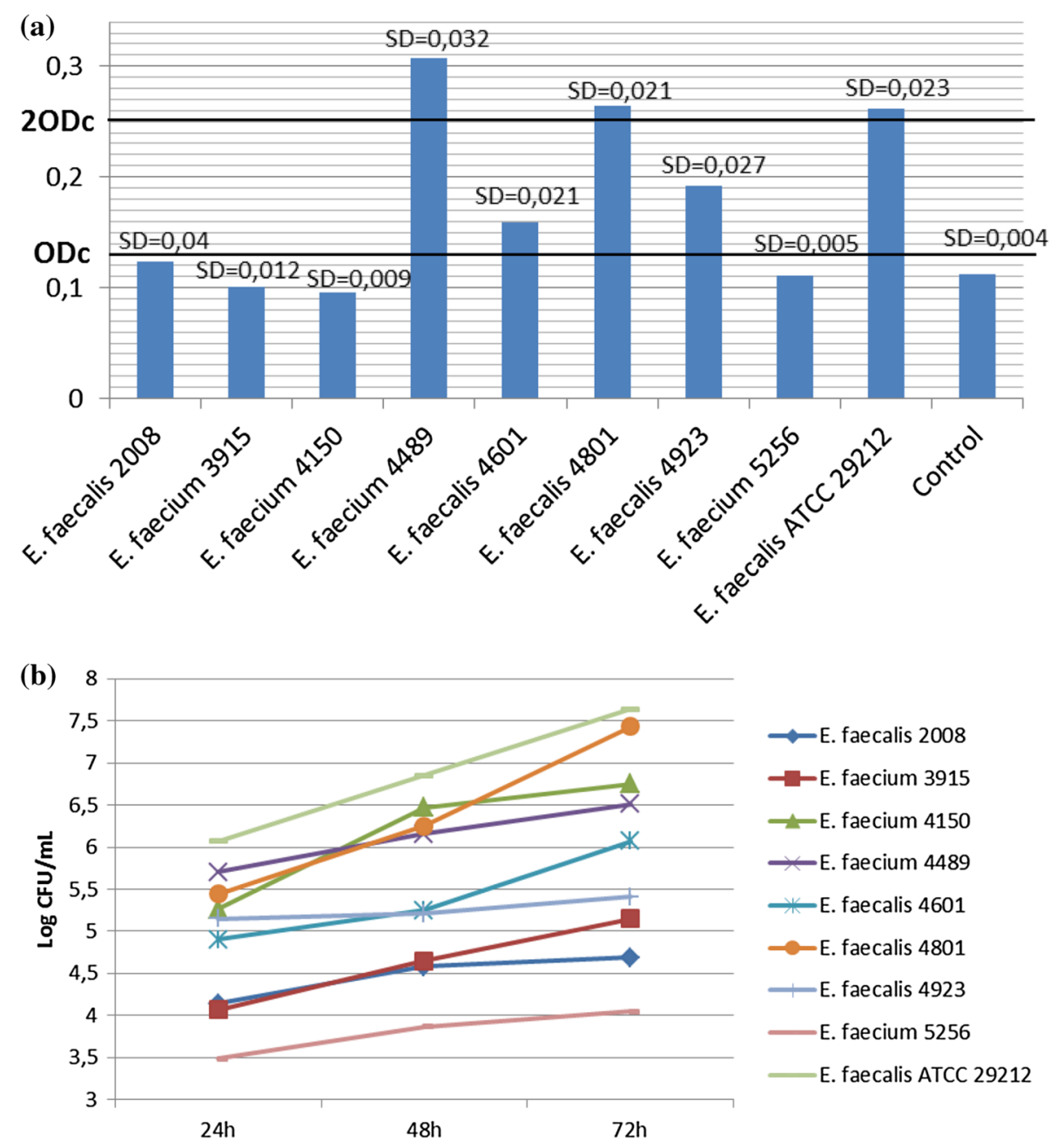

In this study, we analyzed the impact of $\mathrm{Au} / \mathrm{Pt} / \mathrm{Ag} \mathrm{NPs}$ on mature enterococcal biofilm. The cellular viability of biofilms was tested after exposure to $\mathrm{Au} / \mathrm{Pt} / \mathrm{Ag}$ NPs at: (1) minimal concentration that inhibits the growth of planktonic cells (MIC); (2) at minimal concentration that acts bactericidal on planktonic cells (MBC); and (3) at 2-fold higher concentration than MBC $(2 \mathrm{xMBC})$, for $5 \mathrm{~min}, 2 \mathrm{~h}$, $6 \mathrm{~h}, 12 \mathrm{~h}$ and $24 \mathrm{~h}$. The results are summarised in Fig. 6. As expected, the antibiofilm activity of $\mathrm{Au} / \mathrm{Pt} / \mathrm{Ag}$ NPs increased with increasing concentration. The effects of the $\mathrm{Au} / \mathrm{Pt} / \mathrm{Ag}$ NPs on the biofilm were noticeable at concentration of MIC, the number of enterococcal cells in biofilm has decreased from about $0.5 \log$ (after $2 \mathrm{~h}$ ) to nearly 3 logs (after $24 \mathrm{~h}$ ) compared to the control (not exposed to $\mathrm{Au} / \mathrm{Pt} / \mathrm{Ag} \mathrm{NPs}$ ). The higher effect was seen after exposure to $\mathrm{Au} / \mathrm{Pt} / \mathrm{Ag} \mathrm{NPs}$ at concentration equal to MBC, but the highest reduction factors (about $5 \operatorname{logs}$ ) were obtained after exposition to $\mathrm{Au} / \mathrm{Pt} / \mathrm{Ag} \mathrm{NPs}$ at concentration equal to $2 \mathrm{xMBC}$ for a time from 2 to $24 \mathrm{~h}$.

\section{Conclusions}

In this study, trimetallic $\mathrm{Au} / \mathrm{Pt} / \mathrm{Ag}$ nanoparticles prepared using Lamii albi flos extract were characterized by UVVis, FTIR, AFM, TEM, and SEM methods. Also, its antimicrobial potential was studied against Enterococcus faecalis and Enterococcus faecium clinical isolates. It seems that the Lamii albi flos extract can be widely applied for the rapid, economical and environmentally benign green synthesis of trimetallic $\mathrm{Au} / \mathrm{Pt} / \mathrm{Ag}$ nanoparticles, which can be considered as active antimicrobial and antibiofilm agents. In recent years, the resistance to antimicrobial compounds that is displayed by biofilm-forming cells has made biofilms a particular challenge for the treatment of biofilm-related infections.

Herein described the bactericidal effect of trimetallic $\mathrm{Au} / \mathrm{Pt} / \mathrm{Ag}$ NPs against enterococcal biofilm indicates that the nature of interactions between NPs and biofilm in comparison to standard antibiotics and biofilms can be different. Recent studies have indicated that, in contrast to 


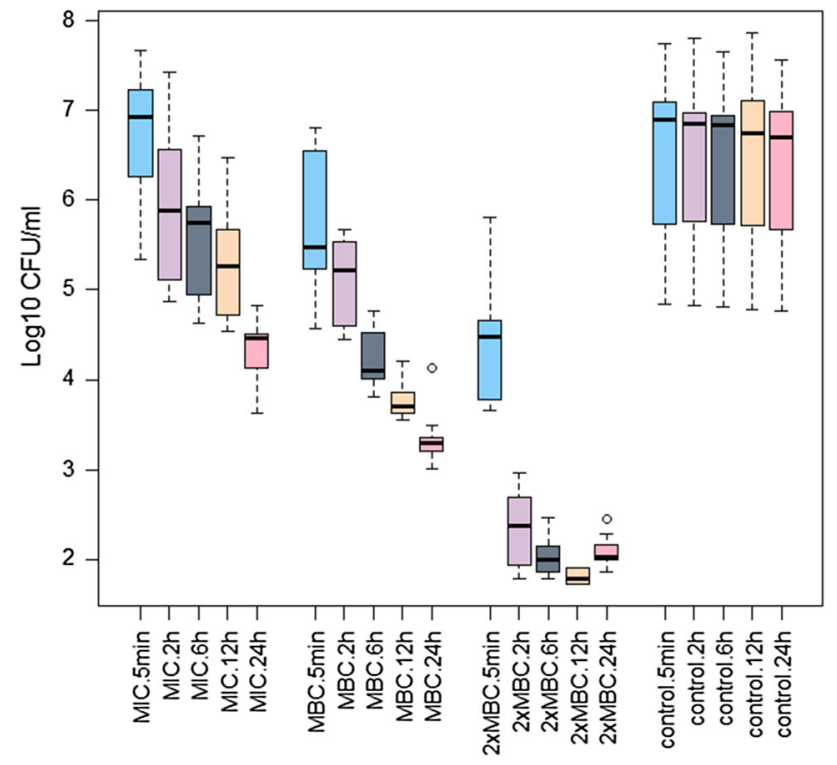

Fig. 6 The antibiofilm activity of trimetallic $\mathrm{Au} / \mathrm{Pt} / \mathrm{Ag}$ nanoparticles. Box plots showing viable cell count as $\log _{10} \mathrm{CFU} / \mathrm{mL}$ from biofilms after treatment ( $5 \mathrm{~min}, 2 \mathrm{~h}, 6 \mathrm{~h}, 12 \mathrm{~h}$, and $24 \mathrm{~h}$ ) with Au/Pt/Ag NPs at concentrations equal MIC, MBC, $2 \times \mathrm{MBC}$, and control

most of the antibiotics, NPs diffuse and penetrate a biofilm, but the effect on bacterial cells in the biofilm depends on the type of nanoparticles [62]. Hashimoto et al. [26] showed that silver nanoparticles inhibited biofilm formation by Streptococcus mutans, while no inhibitory effect was observed with Au NPs. Similar results were obtained by Singh et al. [63] where AgNPs showed strong inhibitory activity against Escherichia coli and Pseudomonas aeruginosa biofilm formation, but the effect of AuNPs was much weaker.

In the majority of studies, the ability of nanoparticles to inhibit biofilm formation was assessed. However, in the treatment of chronic infectious diseases, a desirable feature of an antibacterial drug is related to its ability to migration within a mature biofilm and eradication of microbial cells. Our research has resulted in a significant reduction in the number of viable microorganisms in a mature, 72-h biofilm, at a concentration only two times higher than that of MBC for their planktonic counterparts.

Acknowledgements The authors are grateful to Anthony Cooney for providing language help and Tomasz Gośliński for proof reading the article.

Authors' contribution R.D. developed, designed and performed research in the field of synthesis and characteristics of nanoparticles, discussed the results, participated in writing the manuscript. J.D. developed, designed and performed microbiological research, discussed the results, wrote the manuscript. Both authors read, corrected and approved the final manuscript.

\section{Compliance with ethical standards}

Conflict of interest The authors declare that they have no conflict of interest.

Open Access This article is distributed under the terms of the Creative Commons Attribution 4.0 International License (http://creative commons.org/licenses/by/4.0/), which permits unrestricted use, distribution, and reproduction in any medium, provided you give appropriate credit to the original author(s) and the source, provide a link to the Creative Commons license, and indicate if changes were made.

\section{References}

1. E. Hoseinzadeh, P. Makhdoumi, P. Taha, H. Hossini, J. Stelling, M. A. Kamal, and G. M. Ashraf (2017). Curr. Drug Metab. 18, 2.

2. L. Wang, C. Hu, and L. Shao (2017). Int. J. Nanomed. 12, 1227-1249.

3. M. R. Siddiqui, M. Z. A. Rafiquee, S. M. Wabaidur, Z. A. Alothman, M. S. Ali, and H. A. Allohedan (2015). Anal. Sci. 31, 5 .

4. R. Dobrucka (2018). Iran J. Sci. Technol. Trans. Sci. 42, 2.

5. K. Okitsu, Y. Mizukoshi, T. A. Yamamoto, Y. Maeda, and Y. Nagata (2007). Mater. Lett. 61, 16.

6. L. L. Feng, G. Gao, P. Huang, K. Wang, X. S. Wang, T. Luo, and C. L. Zhang (2010). Nano Biomed. Eng. 2, 258-267.

7. C. J. Zhong, J. Luo, B. Fang, B. N. Wanjala, P. N. Njoki, R. Loukrakpam, and J. Yin (2010). Nanotechnology. https://doi.org/ 10.1039/C0JM02871A.

8. L. Grigoryan, M. S. Abers, Q. F. Kizilbash, N. J. Petersen, and B. W. Trautner (2014). Am. J. Infect. Control 42, 682-684.

9. W. S. Oh, J. A. Hur, E. S. Kim, K. H. Park, H. K. Choi, C. Moon, and B. N. Kim (2014). J. Int. Med. Res. 42, 1335-1347.

10. J. A. Mohamed and D. B. Huang (2007). J. Med. Microbiol. 56, 1581-1588.

11. F. L. Paganelli, R. J. Willems, and H. L. Leavis (2012). Trends Microbiol. 20, 40-49.

12. M. Papadimitriou-Olivgeris, S. Filippidou, E. Drougka, F. Fligou, F. Kolonitsiou, V. Dodou, M. Marangos, E. D. Anastassiou, A. Vantarakis, and I. Spiliopoulou (2015). J. Med. Microbiol. 64, 1270-1276

13. T. Strateva, D. Atanasova, E. Savov, G. Petrova, and I. Mitov (2016). Braz. J. Infect. Dis. 20, 127-133.

14. R. M. Donlan (2002). Emerg. Infect. Dis. 8, 881-890.

15. R. Wolcott, J. W. Costerton, D. Raoult, and S. J. Cutler (2013). Clin. Microbiol. Infect. 19, 107-112.

16. S. Stepanovic, D. Vukovic, V. Hola, G. Di Bonaventura, S. Djukić, I. Cirković, and F. Ruzicka (2007). APMIS 115, 891-899.

17. A. Roucoux, J. Schulz, and H. Patin (2002). Chem. Rev. 102, 10.

18. K. B. Narayanan and N. Sakthivel (2010). Mater. Character. 61, 11.

19. M. Behravan, A. H. Panahi, A. Naghizadeh, M. Ziaee, R. Mahdavi, and A. Mirzapour (2019). Int. J. Biol. Macromol. 124, $148-154$.

20. G. A. López-Muñoz, J. A. Pescador-Rojas, J. Ortega-Lopez, J. S. Salazar, and J. A. Balderas-López (2012). Nanoscale Res. Lett. 7, 1 .

21. N. Yadav, A. K. Jaiswal, K. K. Dey, V. B. Yadav, G. Nath, A. K. Srivastava, and R. R. Yadav (2018). Mater. Chem. Phys. 218 , $10-17$.

22. B. Karthikeyan and B. Loganathan (2012). Mater. Lett. 85, $53-56$. 
23. R. Paduch, M. Kandefer-Szerszeń, M. Trytek, and J. Fiedurek (2007). Arch. Immunol. Ther. Exp. 55, 315-327.

24. M. E. Cuvelier, H. Richard, and C. Berset (1996). J. Am. Oil Chem. Soc. 73, 5.

25. C. Siquet, F. Paiva-Martins, J. L. Lima, S. Reis, and F. Borges (2006). Free Radic. Res. 40, 4

26. M. Rai, A. P. Ingle, S. Birla, A. Yadav, and C. Alves Dos Santos (2016). Crit. Rev. Microbiol. 42, 5.

27. Z. U. H. Khan, A. Khan, Y. Chen, N. S. Shah, N. Muhammad, A. U. Khan, K. Tahir, F. U. Khan, B. Murtaza, S. U. Hassan, S. A. Qaisrani, and P. Wan (2017). J. Photochem. Photobiol. B 173, 150-164.

28. P. Khandel, R. K. Yadaw, D. K. Soni, L. Kanwar, and S. K. Shahi (2018). J. Nanostruct. Chem. 8, 217-254.

29. H. H. Lara, E. N. Garza-Trevino, L. Ixtepan-Turrent, and D. K. Singh (2011). J. Nanobiotechnol.. https://doi.org/10.1186/ 1477-3155-9-30.

30. B. Buszewski, V. Railean-Plugaru, P. Pomastowski, K. Rafinska, M. Szultka-Mlynska, P. Golinska, M. Wypij, D. Laskowski, and H. Dahm (2018). J. Microbiol. Immunol. Infect. 51, 1.

31. K. S. Siddiqi, A. Husen, and R. A. K. Rao (2018). J. Nanobiotechnol.. https://doi.org/10.1186/s12951-018-0334-5.

32. Y. Zhou, Y. Kong, S. Kundu, J. D. Cirillo, and H. Liang (2012). J. Nanobiotechnol.. https://doi.org/10.1186/1477-3155-10-19.

33. M. Hashimoto, H. Yanagiuchi, H. Kitigawa, and Y. Honda (2017). Nano Biomed. 9, 77-82.

34. K. Tahir, S. Nazir, A. Ahmad, B. Li, A. Ullah Khan, Z. Ul Hag Khan, F. Ullah Khan, Q. Ullah Khan, A. Khan, and A. Ur Rahman (2017). J. Photochem. Photobiol. B 166, 246-251.

35. M. M. Mohamed, S. A. Fouada, H. A. Elshoky, G. M. Mohammed, and T. A. Salaheldinb (2017). Int. J Vet. Sci. Med. 5, 1.

36. R. Nishanthi, S. Malathi, S. J. Paul, and P. Palani (2019). Mater. Sci. Eng. C Mater. 96, 693-707.

37. V. Kandi and S. Kandi (2015). Epidemiol. Health. https://doi.org/ 10.4178/epih/e2015020.

38. E. Hoseinzadeh, P. Makhdoumi, P. Taha, H. Hossini, J. Stelling, M. A. Kamal, and G. M. Ashraf (2017). Curr. Drug. Metab. 18, (2), 120-128.

39. Y. N. Slavin, J. Asnis, U. O. Häfeli, and H. Bach (2017). J. Nanobiotechnol.. https://doi.org/10.1186/s12951-017-0308-z.

40. S. Qayyum, M. Oves, and A. U. Khan (2017). PLOS ONE. https://doi.org/10.1371/journal.pone.0181363.

41. K. S. Siddiqi, A. Husen, and R. A. K. Rao (2018). J. Nanobiotechnol.. https://doi.org/10.1186/s12951-018-0334-5.

42. C. T. Handoko, A. Huda, and F. Gulo (2019). Asian J. Sci. Res. $12,1$.

43. Y. Cui, Y. Zhao, Y. Tian, W. Zhang, X. Lü, and X. Jiang (2011). Biomaterials 33, 7 .
44. S. Palchoudhury, Y. L. Xu, A. Rushdi, and Y. P. Bao (2013). IEEE Trans. Magn. 49, 1.

45. K. AyazAhmed, T. Raman, and V. Anbazhagan (2016). RSC Adv. 6, 50 .

46. L. Nejdl, J. Kudr, A. Moulick, D. Hegerova, B. Ruttkay-Nedecky, J. Gumulec, K. Cihalova, K. Smerkova, S. Dostalova, S. Krizkova, M. Novotna, P. Kopel, and V. Adam (2017). PLOS ONE. https://doi.org/10.1371/journal.pone.0180798.

47. R. Dobrucka and J. Dlugaszewska (2015). Indian J. Microbiol. $55,2$.

48. R. Nishanthi, S. Malathi, S. John Paul, and P. Palani (2019). Mater. Sci. Eng. C Mater. 96, 693-707.

49. Z. E. Nazari, M. Banoee, A. A. Sepahi, F. Rafii, and A. R. Shahverdi (2012). Gold. Bull. 45, 2.

50. M. Y. Vaidya, A. J. McBain, J. A. Butler, C. E. Banks, and K. A. Whitehead (2017). Sci. Rep.. https://doi.org/10.1038/s41598017-05976-9.

51. L. Jyh-Gang, C. Siang-An, C. Han-Min, W. Wen-Mein, H. ChiFeng, Y. Yeong-Der, T. Chi-Shun, and L. Yao-Jen (2012). Nanomed. Nanotechnol. 8, 5.

52. F. Yusof and N. A. S. Ismail (2015). J. Appl. Pharm. Sci. 5, 7.

53. N. Elahi, M. Kamali, and M. H. Baghersad (2018). Talanta 184, 537-556.

54. G. Donelli and E. Guaglianone (2004). J. Vasc. Access. 5, 3-9.

55. Y. Seno, R. Kariyama, R. Mitsuhata, and H. Kumon (2005). Acta Med. Okayama 59, 3.

56. G. P. M. Upadhyaya, U. B. Lingadevaru, and R. K. Lingegowda (2011). J. Infect. Dev. Ctries. 5, 365-369.

57. C. de la Fuente-Núñez, F. Reffuveille, L. Fernández, and R. E. W. Hancock (2013). Curr. Opin. Microbiol. 16, 5.

58. H. Van Acker, P. Van Dijck, and T. Coenye (2014). Trends Microbiol. 22, 6.

59. J. Dlugaszewska, M. Antczak, I. Kaczmarek, R. Jankowiak, M. Buszkiewicz, M. Herkowiak, K. Michalak, H. Kukuła, and M. Ratajczak (2016). J. Med. Sci. 85, 4.

60. L. Qi, H. Li, C. Zhang, B. Liang, J. Li, L. Wang, X. Du, X. Liu, S Qiu, and H. Song (2016). Front Microbiol.. https://doi.org/10. 3389/fmicb.2016.00483.

61. C. W. Hall and T. F. Mah (2017). FEMS Microbiol. Rev. 41, 3.

62. K. Ikuma, A. W. Decho, and B. L. T. Lau (2015). Front. Microbiol.. https://doi.org/10.3389/fmicb.2015.00591.

63. P. Singh, S. Pandit, J. Garnaes, S. Tunjic, V. R. S. S. Mokkapati, A. Sultan, A. Thygesen, A. Mackevica, R. V. Mateiu, A. E. Daugaard, A. Baun, and I. Mijakovic (2018). Int. J. Nanomed. 13, 3571-3591.

Publisher's Note Springer Nature remains neutral with regard to jurisdictional claims in published maps and institutional affiliations. 